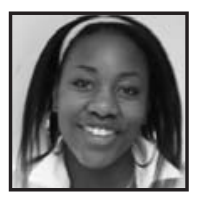

\title{
Stepping Up to Leadership
}

\section{Natalie Domey, Colonel By Secondary School}

\section{ABSTRACT}

The author shares how her role as leader of Black History Club and the United Cultures Club in her secondary school has helped to shape her understanding of leadership. Through the lenses of "stepping up" and "pushing back," she shows how she has come to a deeper understanding of the role of vision, perseverance, resilience, and delegation in leadership initiatives and, further, how these experiences have benefited her in ways that extend beyond leadership of school clubs.

eadership. What is it? The formal definition of leadership is to give direction by setting an example or to act as a guide through one's conduct. To me, leadership is when one "steps up." Further, it means to "push back" when life throws an obstacle in your way. This can be true on a variety of spectrums; however, I believe there are two types of leaders-those who choose to lead and those who are forced to lead. In this article I am choosing to focus on the former. Specifically, I will share some of my experiences and reflections as a leader in my high school.

In the words of Edwin H. Friedman, "Leadership can be thought of as a capacity to define oneself to others in a way that clarifies and expands a vision of the future" (Friedman, Leadership Quotes section, para. 28). Leadership has helped me to redefine myself and feel established as a person. I feel it is the one thing that has helped me find my place in the world. I truly believe that Friedman was right in saying that leadership is to give a vision of the future, and to do so leaders must give direction by example and setting a precedent. In my opinion, no one form of leadership is more important than another. Some leaders may be more valued, but there is 
no variance in importance whether one is leading amongst the community, nationally, globally, or even as the head of a household or, in my case, as the leader of a Black History Club at a local high school. They all require the same skills, techniques, and courage.

In my life I have found myself taking up a leadership role in my community, particularly in my school. At Colonel By Secondary School, I am one of the heads of both the Black History Club and the United Cultures Club, and I am an active participant in a variety of other clubs and teams. Despite my responsibilities on the Graduation Committee and Dance Committee at my school, I feel a great obligation toward the United Cultures Club. Six years ago, my brother and some of his peers founded this club at Colonel By with the goal of bridging the gaps between cultures, highlighting their similarities rather than their differences, and uniting the cultures through these similarities. With each successive year the club has been carried on by a group of leaders who have chosen to step up and head the club. This year I happened to be one of them. The vision that my brother instilled in me from his experience of building the club from the ground up helped me gain the tools to attempt to lead. Theodore M. Hesburgh was of like mind when he said, "The very essence of leadership is that you have to have a vision. You can't blow an uncertain trumpet" (Hesburgh, Leadership Quotes section, para. 3).

Vision is important but so is organization and perseverance. At the beginning of each approaching school year, it is the leaders' responsibilities to meet with a member of administration and book any important dates in which the school space is needed, explain what the intentions of the club for the upcoming year, and most importantly, write up proposals for every event that the club intends to host. When I draft the initial proposal, I anticipate that the administrators will likely find flaws because it is their job to check if proposed dates are already booked, the activity is against school protocol, or if there are just too many events happening at once and would result in too many students being out of class. This is where the frustration begins for me. So I continue with my second, third, and sometimes fourth drafts of my proposals. We work back and forth until an agreement is reached. Once this is attained I must rally together the members of the club and prepare for our first event. This usually ends up being a trying, stressful process as emotions run high, strong personalities clash, and ideas get pushed to the wayside. This is when the strength of the club as a unit is tested, and when my strength as a leader is tested as well.

Sometimes leadership requires a deeper "pushing back" against obstacles. Four years ago, I was one of the founding members of the Black History Club at 
Colonel By. At a school that is not very culturally diverse, the idea was not readily embraced and many students were skeptical about whether this large-scale endeavour could be accomplished or should even be attempted. There was no prior evidence to prove that the project merited an investment of time and we had a difficult time launching the club. Being one of the few black students in my school, and one of two black females in my grade, I felt as though all eyes were on me. I found the pressure overwhelming, and the threats of those students who did not want to hear about Black History did not go unheard. Many felt it unfair that there was a month dedicated to Black History but not to the history of other cultures. While I listened to these comments, I knew it was my responsibility to voice a different perspective. As a member of a race that has been oppressed and still frequently endures racism around the world today, the history of black people is not something that is, or ever has been, taught in many classrooms. Instead, I study the western world and European conquests, exploitation, and colonization; but not a minute of black history. So when I was questioned about the fairness of having a black history month, I explained that my position is that it serves justice.

The Black History Club and what it stands for is a good illustration of my leadership in the community. I made the choice to "step up" and push back against obstacles. That is what leadership is to me. Friedman describes it as being a "capacity to define oneself." The experience has taught me that I can give direction by example, and that I can pave a vision for the future, not only for myself, but also for others. It has taught me that I am resilient. Another thing I have learned from my experience with school clubs comes from the words of Robert Half (2008): "Delegating work works, provided the one delegating works, too" (Half, Leadership Quotes section, para. 24).

I try to integrate what I have learned from school leadership positions into my everyday leadership skills. When I speak of leadership, I am referring to more than leading a school club or team. Everyday one encounters obstacles, and it is whether the choice is made to first "step up" and then "push back" that sets the individual apart from another. This is what I believe defines an individual as a leader not only in school, or a club, or his or her community, but also in life. 


\section{References}

Friedman, E. Retrieved June 10, 2008, from http://www.buzzle.com/articles/leader ship-quotes.html

Half, R. Retrieved June 10, 2008, from http://www.buzzle.com/articles/leader ship-quotes.html
Hesburgh, T. Retrieved June 10, 2008, from http://www.buzzle.com/articles/leader ship-quotes.html

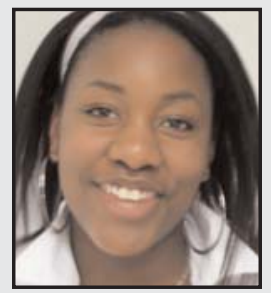

Natalie Domey is a grade twelve student at Colonel By Secondary School in Ottawa, Ontario. She is actively involved in a number of school clubs, groups and teams, and also enjoys reading, music, politics and current events. In the fall she will attend Queen's University to study Global Development. She hopes to travel the world and eventually pursue a career in international development. 